\title{
Directional Antenna Beam Controlling Method using Fuzzy Logic System
}

\author{
Malathi.B.N \\ Senior Lecturer \\ Department of E\&COE \\ Caledonian College of Engineering, Muscat
}

\begin{abstract}
This paper is an effective method to search or a quick scan the easy spot for directional antenna beams, and it is used for high speed data transmission in millimeter wave. The present paper proposes a method using the Fuzzy Logic control system for giving maximum data rate transfer using directional antenna[1]. The methods of transmission is using TDD, and it sends the control instructions of the antenna. User can send and to receive a huge scale of data in millimeter wave BW bandwidth. Antenna signal at initial stage influences a poor performance on communication. The fuzzy logic control system finds the exact reliable spot. The fuzzy logic control system FLC, Rule based interlacing is used the maximum to minimum inference procedure. De-fuzzification is used at the gravity center computation [3].
\end{abstract}

\section{Keywords}

Fuzzy Logic Controller, Directional Antenna, beam control

\section{INTRODUCTION}

Today essence of communication has increased drastically . In this fast moving world every person looking for speed and at ease of communication. In local bandwidth, there is lack sufficient space and it is too cost for normal usage. Spectrum space and free frequency band width set is $2.5 \mathrm{GHz}$ or more. Therefore user assume that in the field of communication a beam of antenna could store/save an easy spot alignment then its possible that Gigabytes per second GBPS transfer could take place[1]. If the communication is disconnected or host has been turned off, a quick search for an easy/easy spot for other directional antenna and to maintain communication. Considering real time situation to align and adjust directional antenna and to fix beam direction is dangerous for SNR suppression or some technical disconnection [4].

The paper proposes a efficient method to search a easy spot in between each individual stations on directional antenna view and maintains its live state for a efficient period of time. The present proposed method uses the Fuzzy Logic Control system [4]. User will use Time-Division Duplex technique as a data or information transfer method, and it sends the control data of antenna. For stimulated results the easy spot has been generated by directional antenna.

\section{LITERATURE REVIEW}

The present paper deals with concept of wireless communication with high gain and data transfer rate. In the existing or previous system the antennas are used to triangulate for locations of receiver in Omni direction i.e. in all directions and once connection is established between two antennas the data transfer rate is a key factor for efficient system. In this existing system the data transfer rate is not consistent instead it keeps on fluctuating because of many reasons like directionality or the priority of antennas the locations and climatic conditions. This drastically effects the speed of data transfer.

In the present proposed system the antenna maintains directionality once the connection is established. The antenna first broadcasts the signal to all the recipients and tries to track down the location on directions and gives the maximum power towards the recipient direction and gives the maximum bit rate transfer. This system uses fuzzy logic control and tries to get a sweet spot or easy spot. This sweet or easy spot has the maximum gain where the antenna has to be focused while transferring. This will also improves the signal to noise ratio over the period of time. Even when the link is broken due to many external conditions the previous scanned sweet or easy spot is obtained directly from the logs and gives a direct connection reducing the interruption or the data transfer.

\section{PROPOSED METHOD}

In the networks of beam, searching and saving a suitable direction of beam is essential to avoid Signal To Noise suppression and disconnect from Host. If communication is lost by power failure or technical break down of antenna system, etc, then a quick scan for the easy spot of other arrays of antenna and to maintain the link. fig 1 shows the ideal arrays of antenna beam sweet/easy spot. fig 1 shows the intensity of the beam from station and the highest point is the sweet/easy spot [5].

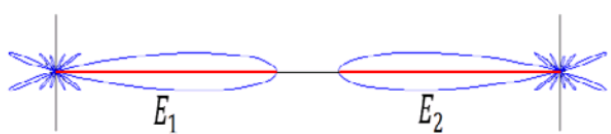

\section{Fig 2.1: Ideal array beam antenna}

$\mathrm{P} 1$ and P2 are two values of the intensity of particular individual station where as the value of distance varies in terms of angle. The angle between particular individual station made equivalent to the $\theta 1$ and $\theta 2$ angles $P 1$ and $P 2$ are given in the following equations

$$
\begin{aligned}
& P 1=\sum_{n=1}^{N / 2} W n \cos \left((2 n-1) \frac{\pi d}{\lambda}(\sin \theta-\sin \theta 1)\right)->(1) \\
& P 2=\sum_{n=1}^{N / 2} W n \cos \left((2 n-1) \frac{\pi d}{\lambda}(\sin \theta-\sin \theta 2)\right)->(2)
\end{aligned}
$$

Where the parameters $\mathrm{Wn}$ is the weight of array, $\mathrm{d}$ is the distance, and $\lambda$ is the wavelength of antenna and the $\mathrm{N}$ denotes number of array[7].

Easy spot search is to manipulate the optimized value of beams of directive antenna between two stations names P1 
and P2. Information direction of each beam for each station becomes at ease and it is also finds easy spot by utilizing the multiplication factor of $\mathrm{P} 1$ and $\mathrm{P} 2$.The required function " $\mathrm{z}$ " is described as equation (3). Required value is a focused point when optimized function becomes high i.e., the value is maximum

$$
\mathrm{Z}=\mathrm{P} 1 * \mathrm{P} 2 \quad->(3)
$$

The following method was to find the appropriate location for easy spot using the fuzzy logic control system .Figure 3 is proposed method flow chart.

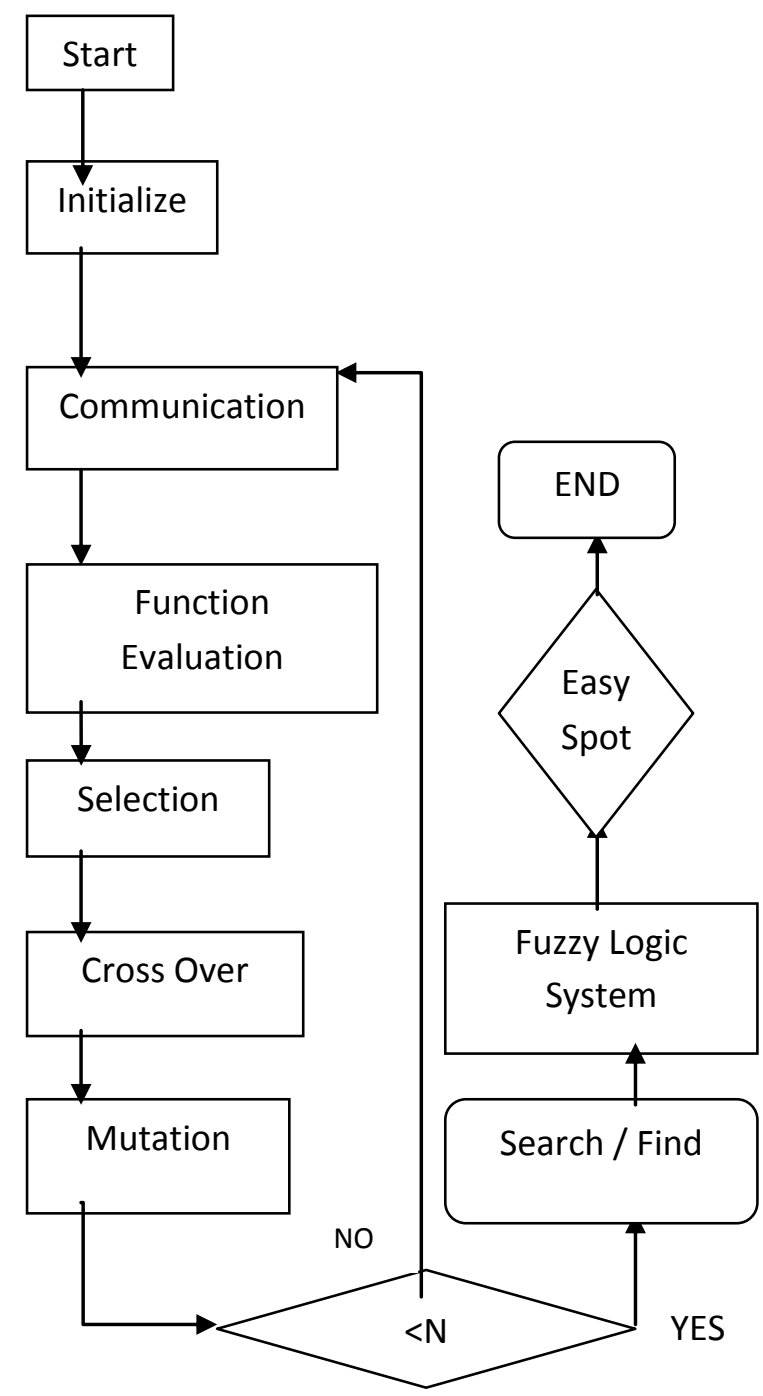

FIG 3.1: Proposed Method Flow Chart

\section{FUZZY LOGIC CONTROL SYSTEM FOR EXACT SWEEP/ SEARCH FOR}

\section{EASY SPOT}

Fuzzy logic Control system search's the exact easy spot much faster than the Genetic Algorithm. The approximate easy spot is found over the focused area. The present discussed method is to search the various intensity of the current beam and previously captured beam and eventually to find the antenna's degree of its movement or change in its angle of view by the use of fuzzy logic control system.

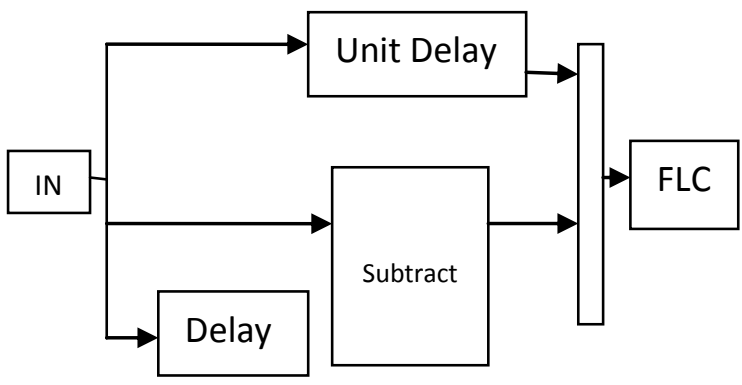

Fig 4.0: Block Diagram of FLC

If ( $\mathrm{E}$ is $\mathrm{PB})$ and (del $\mathrm{E}$ is $\mathrm{PM})$ then (del $\mathrm{U}$ is $\mathrm{PB}$ )

The following figure is the input member ship function of fuzzy logic control system

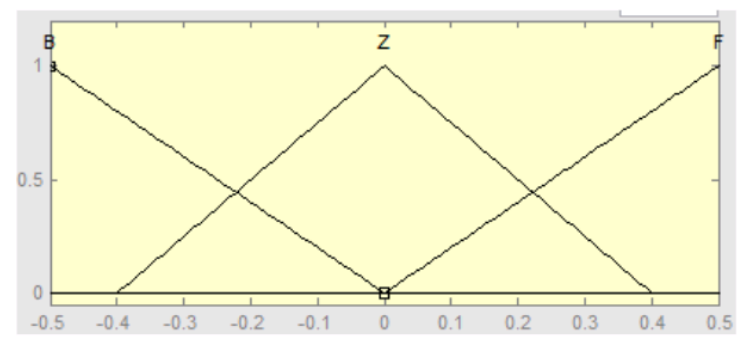

Fig a: Present Beam Intensity

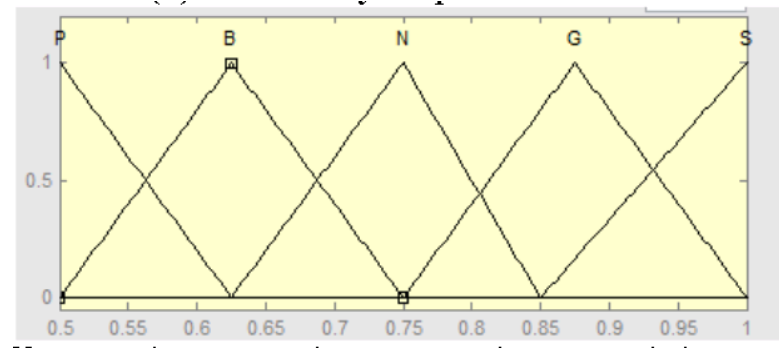

Fig b: Variation between previously captured beam and present beam

Fig 4.1: input member ship function of fuzzy logic control system

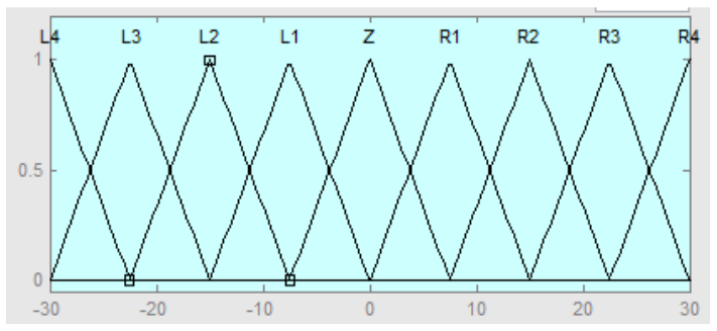

Fig.4.2. Output functions of fuzzy logic control system.

Table 4.1: Fuzzy Rule

\begin{tabular}{|c|c|c|c|}
\hline & B & Z & F \\
\hline $\mathbf{P}$ & L4 & R2 & R4 \\
\hline $\mathbf{B}$ & L3 & Z & R3 \\
\hline $\mathbf{N}$ & L2 & Z & R2 \\
\hline
\end{tabular}




\begin{tabular}{|c|c|c|c|}
\hline $\mathbf{G}$ & $\mathrm{L} 1$ & $\mathrm{Z}$ & $\mathrm{R} 1$ \\
\hline $\mathbf{S}$ & $\mathrm{Z}$ & $\mathrm{Z}$ & $\mathrm{Z}$ \\
\hline
\end{tabular}

Fuzzification is maximum to minimum ratio cination, and Defuzzification calculated by using center of gravity

\section{SIMULATED RESULT}

The standard parameters of the stimulated results are seen in following Table 2 . where the parameters are selected by $\mathrm{N}=$ $35, \mathrm{~d}=0.01, \lambda=0.0025$, Crossover Rate $=0.75$ and the Mutation Rate $=0.08$, the result obtained as follows

\begin{tabular}{|c|c|}
\hline PARAMETER & VALUE \\
\hline Size of Population & $2-8$ \\
\hline Generation & $10-20$ \\
\hline Crossover & 1.0 \\
\hline Mutation & 0.05 \\
\hline
\end{tabular}

Thus the above parameters will give an overview of ranges of value which the parameters are concerned. The standard parameters like the Size of population and Signal strength of generation and the period of cross over and the Mutation or mixing up of signal giving rise to new form of signal will be measured and compared time after time.

Simulations are done in MATLAB and fewer minor lobes are reduced drastically and the back lobes power consumed is very less when compared to normal directional antenna. Thus improving the performance capability of antenna and data transfer rate in a specific direction i.e. it covers all the consumer users in a specific direction in which it is focused towards.

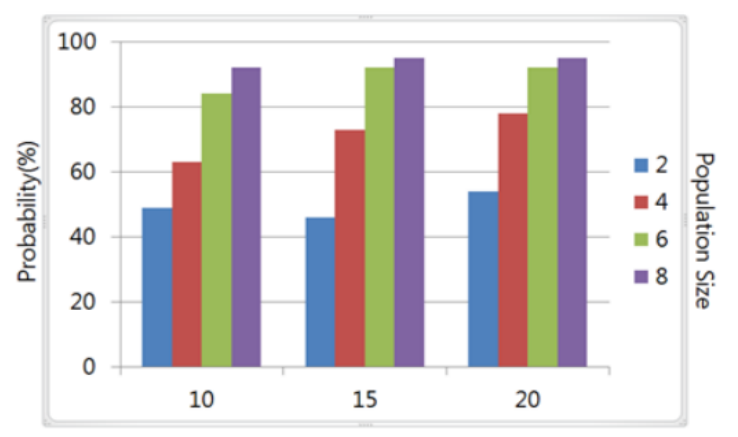

Fig 5.1: Generation

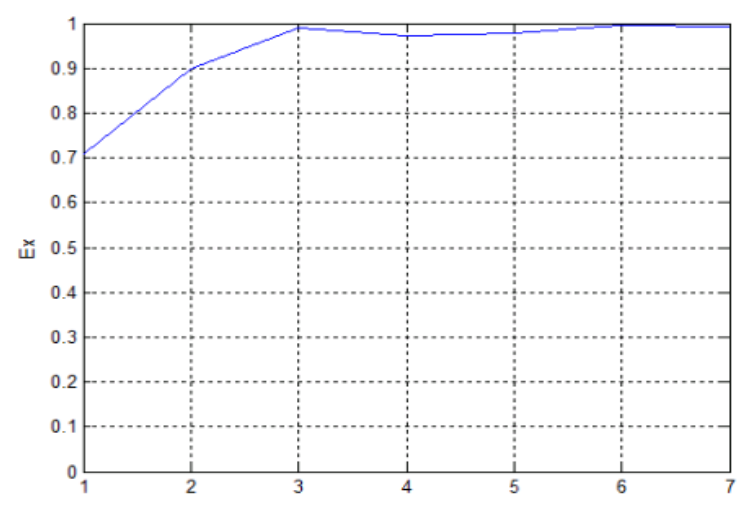

Fig 5.2: Fuzzy Logic Control System Stimulated Results

\section{CONCLUSION}

This present paper proposes a method to scan and find the easy spot for beam of directional antenna and to give high speed data transfer in millimeter-wave on the link directional antenna. When particular station individually transmits information using Time Division Duplex, they send antenna information and also search for the easy spot using the obtained data. This method is to use fuzzy logic control system locating the exact easy spot. The present scheme is evaluated by the simulated results. This method can search quickly for the easy spot for directional antennas, and fixes the angle and few depending parameters on to it. Hence the transmission takes place in the form of Giga-Bytes per second.

The Future scope of this project will be transmitting of data or bits of information with much higher rate in the count of Gigabits per second or even higher. The transmitting antenna will be high power antenna the receiver will be a Mobile unit with regular micro strip antenna or normal receiver antenna. The Directional antenna or beam antenna which is focused on the receiver antenna end will be of higher directionality in power transmission so that minor lobe power consumed will be very less. This technology will changes the Data rate or speed of transfer greater than 4G/LTE technology which are at the present trend.

\section{REFERENCES}

[1] Sang-Hun, Choe (13 May 2013). "Samsung Advances Toward 5G Networks". New York Times (The New York Times Company). Retrieved 29 October 2013.

[2] Steven J. Vaughan-Nichols (21 June 2013). "Gigabit WiFi: 802.11ac is here: Five things you need to know". zdnet.com. CBS Interactive. Retrieved 29 October 2013.

[3] Antenna steering for an access point based upon probe signals, Ipr Licensing, Inc., May 16, 2006

[4] Antenna steering and hidden node recognition for an access point, Ipr Licensing, Inc., Sep 5, 2006

[5] Method for steering a smart antenna for a WLAN using a self-monitored re-scan, Interdigital Technology Corporation, Feb 20, 2007.

[6] Dynamic frequency selective surfaces, Delphi Technologies, Inc., Mar 13, 2007.

[7] Wireless communication method and apparatus for selecting and reselecting cells based on measurements performed using directional beams and an omnidirectional beam pattern, Interdigital Technology Corporation, Jan 29, 2008.

[8] K.-H. Su and C.-C. Kung (2005), Adaptive fuzzy control position for electrical servo drive using total sliding mode technique, IEEE Proc. Electrical Power Appliances Vol.152, 6 .

[9] Li Xin Wang, Design and Analysis of hierarchical fuzzy logic system, IEEE Tans. On Fuzzy Logic systems. vol. 7, no. $5,617-624$

[10] Lab Volt Ltd., Digital Servo Motor Control, First Edition, Canada, 2010. ISBN 978-2-89640-391-2 
[11] A. Seneviratne, Z.G.Zhou R.Hsieh, S-MIP : A seamless handoff technique for mobile IP, in Proc. IEEEINFOCOM, Apr. 2003.

[12] R.M.Peters, Synthesis of Mechanism for the Stabilization of Radar Antenna, 'Mechanism and Machine Theory', Vol. 13, pp. 369-389, 1978.

[13] Chuen-Chien-Lee, Fuzzy Logic Control Systems: Fuzzy Logic Controller Part-I, 11Xr Transactions On Systems. Man, Ani, Vol 20. No. 2.

[14] J.T Spooner and K.M Passino, "Stable Adaptive Control Using Fuzzy Systems and Neural Networks," IEEE
Transactions on Fuzzy Systems, Vol. 4, No. 3, pp. 339 359, August 1996.

[15] R.L.Pheysey, AIM 9L, Simulation-Parameters, Navy Weapons-Center, China-Lake, California NWC, July 1975.

[16] C.C.Lee., Fuzzy Logic Control Systems- Fuzzy Logic Controller, IEEE Trans. on Systems, Man \& Cybernetics, 20 (2), pp. 404- 435, 1990.

[17] S.Chowdhury, G.Taguchi, and Y.Wu, Taguchi's The Quality Engineering Handbook, New York: Wiley, 2005. 